\title{
A Presence in Time and Space
}

\author{
By George Bagley \\ Spring 2008 Issue of KINEMA
}

\section{A PRESENCE IN TIME AND SPACE: AUTHORITY AND MEANING IN THE RECEP- TION COMPLEX}

Consider Freud's dilemma while sleeping on a train. Upon waking, he mistakes the image reflected in his train compartment window as an elderly gentleman, only to realize in time that "the intruder was nothing more than [his] own reflection." (1) This brief, mistaken visualization presages the intricate relation between representation and understanding, and thus jump-starts a workable metaphor for the reception complex proposed here. Before him in the train's window Freud mistakenly regards an image and takes it at face value, the verifiable picture of a moment in time and space, yet in truth this is simply a manifestation, not the literal picture of that very moment, but a reproduction housing within itself a potential for eventual understanding. It's only after negotiating the field of this mirrored view, the reflection of the bench upon which he is seated and the movement of other passengers about him, only after his own speculation upon this image, that Freud finally grasps a suitable meaning to what he beholds in the window before him: the image of himself.

Freud's passing observation reveals a critical truth. In the light energy reflected in the darkened window of a speeding train resides potential meaning. Freud's original mistake, however, is his alienated view. He attempts to understand this vision before him by a reduction, by the image as original and sovereign, possessed of its own visual authority. What he apprehends - thinks he apprehends - is the reflection of another by virtue of that visual sovereignty, yet upon his own contemplation of those images, his own speculation upon them, the picture becomes clearer. His negotiation of the visual frame, then, finally leads Freud to recognize the real meaning of the image, the self that he views, setting his mind at ease.

The leap from Freud's observations to questions of reception and meaning may seem an ambitious preface to a discussion on the nature of reception, though when placed in a negotiation context the connection becomes more apparent. I would like to begin here. That is, I would like to not only take the proposition of negotiation as Mayne, Hall and others have termed it and extend it to the field of television reception, but I would also like to place negotiation in a particularly visual, or visually representative, context. This isn't to suggest any kind of overarching authority visualization may possess over other means by which textual messages may be received and negotiated. Rather, I will attempt to expose textual comprehension's dependence on, among other things, representation and a television text's potential meaning, suggesting that representation is only a beginning, that a text's meaning derives from the significant intersection between representation and the work it imposes on the receiver, a labour of reception, a representative frame beckoning negotiation. This will all be prefaced by my preliminary presumption that deterministic modalities in television studies insufficiently define reception. The television mirror offers not the verity of actual existence, the self in actual reflection, the undeniable and literal view of self and the coterminous world, but the representation of existence, a frame of potential meaning only finally realized when acted upon by the imaginative faculties of receiver. I must first, however, acknowledge the limitations that prevail in this arena. These are umbilically linked to the dominant modality of our discipline's investigations and its mistaken reliance on the notion of linear causality.

\section{Linear Authority}

If I assert that television reception research may contain some methodological shortcomings, then I must coincidentally assert the dimensions of those inadequacies. Our prevailing interrogations have inexorably led to our commensurate reliance on positivistic models. The only certainty in television research, it has historically been assumed, comes from our ability to empirically measure the medium's effects on its viewers, which springs naturally from some prevailing questions regarding the nature of television reception. How, for instance, can we definitively ascertain the nature and degree of television's effects upon its receivers? To what degree can those effects be isolated, measured and either individualized or generalized to larger populations? These are understandable questions. The complexity of the television medium, the protean nature of its 
images and sounds and, perhaps most daunting, the seemingly endless variability of those receiving it summon our natural tendency to order the apparently disordered. The medium's rapid ascendancy during the 1950s and 60s furnishes a natural origin for what has become the conventional methodological approach in communication and television studies, a direction valorizing the collective nature of the television experience. Medsger notes that as a truly mass medium with its correlative audience, and with portentous claims from varied and significant sources such as Marshall McLuhan and Newton Minow, researchers and the public grew increasingly interested in the effect of television messages upon the audience en masse. ${ }^{(2)}$ Quantitative methodologies, rooted as they are in a linear logic of ordering, create a more embraceable scholarship by narrowing the field, theoretically rendering it all into concrete, understandable terms. Orientations to the specific, it's assumed, will establish as precisely as possible a direct causal link to the general.

And this unfailing optimism is more than simple window dressing. The logic of ordering and generalizing has always been the concrete underpinning of sociological research like this. Beginning in the very birth of that science, Herbert Spencer asserted the value of researching people as groups. "The nature of the units," he stated, "necessitates certain traits in the aggregates." (3) Only a few years later, Ward and Dealey terminally coupled Spencer's advocacy for a human science with the precision of mathematics, the verifiability of statistical measurement. ${ }^{(4)}$ So television research predictably proceeded along such sociological lines, predicated upon the awareness of a mass audience watching the same thing at the same time in roughly the same circumstances, further ordered upon statistical precision. The perpetual focus in all this seems to be what does this variable do? How may it be isolated, measured, verified to determine its effect upon the viewer? And the field of television research is replete with various strategies designed to do just that. For instance, past research has interrogated the nature of information retention in television viewing temporally measuring subjects' actual look at the televisual image. The focus of this particular endeavour was to discover whether there were any correlation between the duration of that look and one's ability to retain certain information acquired when viewing, ${ }^{(5)}$ a study whose conclusions are ultimately gathered from direct manipulations to the viewing patterns of select focus groups. Others have probed the possible connection between viewing a violent television depiction and subsequent violent actions in individuals,${ }^{(6)}$ or whether first, third and fifth graders exposed to flashback scenes could effectively decipher complex atemporal sequencing in television crime dramas. ${ }^{(7)}$

Approaches like these are appealing precisely because they present themselves as linear and predictable, thus reliable. Measuring exact viewer responses to individual stimuli, their validity derives from rigorous statistical isolation, a final conclusion arrested from the wealth of variables emerging at the intersection between viewer and image, and predicated upon the notion that effects proceed from the text, in other words, the television text exerts its authority upon its audience. This is a tempting perspective to entertain. To understand the nature and extent of the television text's connection with its viewers, it's held, one may simply unravel the linear connection that presumably exists between them. Only by such a logic, and through the verifiability of replication, can we hopefully acquire some kind of intellectual grasp on the protean phenomenon that is television reception.

\section{Alternate Positions}

Yet effects orientations, like Freud's mistaken apprehension on a midnight train, represent an elusive vision marshalled upon a mistaken security. Freud's is initially an empty reception. He fails at first to anticipate that to finally arrive at a plausible and accurate meaning he must visually negotiate the representation before him. His initial reception of the reflection relies upon his immediate visceral awareness. And just as Freud presumptively endows the reflection he sees with unwarranted authority, so effects orientations endow the television text with its own authority, one autocratically exerting itself upon the receiver, thereby obviating any real sense that the television frame may potentially open itself to some kind of resistance, or negotiation. Moreover, such methodology relies on the overarching notion that the viewer is, to one extent or another, a tabula rasa, a vessel passively awaiting the stimulus of the television medium.

The case against such linear authority has been effectively, if not quietly, argued upon some rather obvious logical lines raising their own unique questions. Don't effects orientations necessarily abbreviate the complexities of viewership, severing the reciprocal role of self in that process, ignoring fundamental questions of homology and heterogeneity, the extent to which viewers either uniformly reflect television content or alternately structure out their own particularized reading of it? Is reception nothing more than the product of 
the monolithic television text, its messages trickling through one's consciousness like the quiet, steady drone of a leaky tap? Such questioning precedes a different way to view the reception complex as a phenomenon really too complex to be reduced to"macro perspective[s]," ${ }^{(8)}$ generalized assumptions drawn from statistical measurements attempting to account for a phenomenon - television reception - "somewhat resistant to quantitative methodology." (9) Viewers are something considerably more than a tabula rasa, as Morley asserts, actually "active in all kinds of ways" during the reception process. ${ }^{(10)}$

Morley's position, of course, supplants empiricism's linear authority with the variability of heterogeneity, and this is a perspective with deep roots. The idea that textual readings are actually heterogeneous is the relatively recent reaction to reception formulations emerging in the 1970s, mostly in cinema studies, and express a dissatisfaction with notions that a given text would exercise some kind of monolithic authority over its receiver(s) by idealizing a receptive viewer framed by Freudian ideological discourse. As Judith Mayne suggests, that theoretical position presumes a "cinematic apparatus...fully saturated with the ideology of idealism and Oedipal desire" and a spectator who is ideally "postulated by [that] apparatus."(11) Mayne's elucidations help one understand the degree to which this reception pendulum has swung. In the absence of a deterministic text, one reacts accordingly, that is, the natural antithesis to determinism is to view reception as oppositional. Such readings presume a receiver who, in the process of structuring his or her own particularized reading of a given text, actually subverts the text's dominant meaning. Mayne calls this theoretical bifurcation the "paradox of spectatorship," noting that in contrast to a firm reliance on linear causality, oppositional readings suggest a receiver who exercises a degree of freedom with respect to the position of the textual apparatus, may in fact exist in an "imperfect relation to that ideal," transposing this with his or her own particularized reading. ${ }^{(12)}$

To justify such a perspective, theorists invoke the receivers' inescapable binds to the "languages, the concepts, categories, imagery of thought, and the systems of representation" Stuart Hall so clearly affirms individuals accumulate as they live out their lives among different social groups and classes. ${ }^{(13)}$ And this prescription is not confined to either the cinematic or literary domain; in the corners of television studies, one encounters recent, and rather pronounced, attempts to literally apply Hall's ethic. Hall, along with Anten and Cakim,(14) for instance, interviewed US and international television viewers to determine how one's national cultural identity informs media interpretation, or Fetveit ${ }^{(15)}$ who, pursuing a similar logic, argues for contextual readings of photographic reality by drawing upon an interesting semiotic view: that photographic discourse is far from unified, that it will vary from context to context and that to understand any photographic discourse one must possess a working semiotic understanding of the particular context of reception.

Approaches like these may appear to offer up a reasonable alternative to the error of assuming a linear textual authority, yet upon closer examination they eventually yield their own illusion. Their danger is, like presumptions of the deterministic text, their own disequilibrium. Preoccupations with the ideological self actually invert the linear authority asserted by effects-oriented methodologies. In other words, these latter orientations to the self, and the contexts that constitute it, seem equally determined to proceed from a single source, in this case human consciousness, in the process becoming, Mayne suggests, "one more totalizing system." (16) The natural self consequently now emerges as our alternate focus, the narcissistic centre of our consideration, the vortex of the reception complex. The television text, meanwhile, comes off as infinitely variable whose reading solely depends on one's social, cultural and ideological position.

Some have valiantly sought their own theoretical means that would synthesize these seemingly disparate and irreconcilable positions. Hoijer's remedy, for instance, uniquely blends quantitative, effects measurements with more subjective considerations of the individual. Reception, she claims, proceeds first from the complex dialectic between inner and outer spheres of experience, each acting upon the other, negotiating in a continuous give and take, ${ }^{(17)}$ and finally intersecting with the television text. By exposing subjects to documentary medical programming and measuring their responses, Hoijer uniquely merges statistical findings with comparisons against each subjects' individual sociological data in an attempt to account for a highly subjective reception not reducible to generalization. By such methodology, Hoijer seeks to represent a television text possessed of its own meaning but one also qualified by the context of the receiver. Other research proceeds similarly, suggesting, like Hoijer, that the viewer is more than a passive receptacle for the television image, that he or she brings to the process a context of understanding informing how the image is received. McKee and Pardun, ${ }^{(18)}$ for instance, exposed seven focus groups of college students to selected 
music videos depicting one form of religious imagery or another. They concluded that while their subjects on various levels indeed universally attended to the religious imagery, their signification of that imagery varied depending on one's context of understanding, the complexities of individual consciousness brought to reception by the viewer.

Studies like Hoijer's or McKee and Pardun's ostensibly locate both medium and consciousness within an egalitarian context, a view of reception as not merely the inscription of meaning either to or from televised stimuli - external acting upon internal; internal upon external - neither variable nor consciousness foregrounded at the expense of the other, but the intersection between consciousness and medium, a dynamic not reducible to either part alone, not subject to a hierarchy of stimuli. One faces thus a tempting conclusion. If these methodologies may be blended such as this, then we may have discovered our rescue from the myopia of isolationism and strict linear causality, that only via such an approach may we discover that elusive, robust account of the television reception complex.

\section{Reproductive Texts}

Still, despite their unique equation of text and self, blended methodologies like these nevertheless fail to depict the depth and detail of the reception complex which takes place in a universe of representation. By neglecting this single underpinning of television reception, Hoijer and others fail to account for the exact terms of the intersection between text and receiver and the subsequent formulation of understanding. There is another way to view this. I would propose that questions of authority, when viewed as an end, take one down an erroneous path if what we're after is that robust account of the reception process. Ultimately, understanding reception must be less concerned with questions of textual authority, empiricism or even consciousness than with the more important question of the construction of textual meaning. I realize that I risk invoking the smoke and mirrors of semantic distinction here, yet the difference between these semantics is actually very notable as the latter ushers in what I would like to describe as a reception complex. And there is no more appropriate point for wading into questions of textual meaning, particularly in a contemporary medium such as television, than Walter Benjamin's seminal and articulate essay, The Work of Art in the Age of Mechanical Reproduction, for it is this dilemma of authority and meaning which Benjamin so carefully elucidates and which eventually stages a persuasive understanding of the reception complex.

Benjamin, focusing largely on photographic media, most specifically film, centrally questions exactly what happens to an object's authority once it is represented by mechanical or technological means. Once civilization accessed those means to represent and reproduce natural objects, and our consequent ability to depict them in perpetuity, there followed a natural consequence. Mechanical and technological representation, Benjamin maintains, severs the natural relation between the object and "its presence in time and space."(19) To understand that presence, Benjamin points to the natural object, unreproduced, unrepresented, the experience of immediate and unmediated witness. In all instances, the natural object held to just such a reception will exercise its natural authority, or what Benjamin refers to as its aura, a complex of "its substantive duration...its testimony to the history which it has experienced," ${ }^{(20)}$ over its receiver. Yet what happens when this kind of unmediated witness faces the interposition of mechanical or technological reproduction, when the natural object is detached, as it were, from its particular and unique place in time and history, its existential testimony to its permanence, its natural authority?

This is the dilemma Benjamin interrogates, and he offers as example the religious statue of a divinity. Located as it is in the holy place - the interior of the temple, the cathedral chapel - its presence there testifies to its temporal and geographical meaning and authority, yet once reproduced, photographed, distributed, the object is naturally severed from its uniqueness, must undergo a "qualitative transformation of its nature," for it is now open to multiple and varied contexts of reception. ${ }^{(21)}$ Detached from its existential testimony, its position and permanence, its aura, the object now seeks a new meaning.

Importantly, Benjamin resists confining his discussion to a strict artistic context. All objects naturally perceived, in other words, subjected to unmediated perception, exercise their aura upon the receiver. They register, at the point of reception, their contextual meaning, their significance in time and space. If, on a summer evening, one apprehends the setting sun over the sea's horizon, this singular perceptual act registers a natural authority, a visual significance dependent upon the complete context of the moment of the reception. If, on the other hand, that moment is captured by another medium, immortalized and reproduced for mass 
distribution and, I would add here, mass reception, then natural authority is evacuated and contextual significance becomes a relative proposition. In fact, the object no longer depends on its originary context; its meaning is now open to interpretation, its significance dependent upon a new reception.

So, in the absence of an original aura, what is left? What do we make of a medium such as television whose representations exist in this void of authenticity? Is our only reaction to ride out the pendulum swing and view the television text like Morley, as nothing more than a catalyst, itself now the empty vessel awaiting meaning only the receiver may endow? Certainly questions of authority naturally disrupt the apparent methodological harmony of effects orientations, yet far from a barren theoretical void, they simultaneously usher in fertile new arguments enriching television reception studies. Benjamin himself actually offers a single, critical observation that clues the reader toward a resolution of the paradox. The aura is gone, depleted because the object is now a representation, but the act of receiving this new representation is nevertheless an intersection. "Above all," Benjamin claims, the reproduction "enables the original to meet the beholder halfway," ${ }^{(22)}$ performing its work upon the receiver, "stir[ring] the viewer" in new ways. ${ }^{(23)}$

\section{Text and Negotiation}

This intersection is just what Judith Mayne clarifies. She issues the call for a different approach less dependent "on large theories that can account for everything, and more on the play and variation that exist at particular junctures" of spectatorship. ${ }^{(24)}$ She finally argues for understanding negotiation, a perspective less concerned, she maintains, with the "status of the text" or the contestable position of the viewer, than with how responses to textual messages actually represent a process of labour, thus a means of addressing a point of reception. Mayne is justifiably troubled by reception interrogations focusing exclusively on questions of "resistance and agency" $(25)$ or, put another way, the limitations of not only deterministic readings of a given text, but oppositional readings as well. This is a well-rehearsed antagonism, and for Mayne a limited one inasmuch as it overlooks one simple prospect: that a textual reading may actually include components from both dispositions. Negotiation, by its very name, implies some kind of work upon something already in existence. In textual considerations such as television studies, this would imply that the notions of authority and determinism are actually invalid, that the text can't entirely be emptied of a meaning, and I think this is perfectly consistent with Benjamin's claim. It is indeed the case that technological reproduction severs the object from its organic authority, but the reproductive act itself ushers in a new context for reception dependent upon this intersection, a new formulation that at once distances us from questions of authority and toward a richer theory of meaning construction within a reception complex.

In an intriguing essay, Patrick Keating ${ }^{(26)}$ cites the series of writings by Benjamin Harshav on the nature of textual meaning in which Harshav renders this very intersection between text and receiver in a symbiosis of Internal and External Fields of Reference, and so appeals to the context of meaning construction argued here. Harshav interrogates the relation between the fictional world and narrative understanding, and his insights, though focused on the field of literary meaning, specifically fictional texts, are particularly helpful and quite suited, I think, to the macro-discussion of meaning construction since they explore the larger, complex relation between representation and reception.

Harshav points to what he calls "additional texts," which form the referents upon which representation and subsequent meaning construction depend, a complex relation between these Internal and External Fields of Reference. The Internal field of Reference is, quite simply, the universe of representation, "a whole network of interrelated referents of various kinds: characters, events, situations, ideas, dialogues, etc." contained within the particular text. ${ }^{(27)}$ Keating elaborates, stating that the "text's world does not exist in the real world,"(28) and one cannot presume the text's diegesis to discover some authority these representations lack. This must be so because as symbolic composition, television's field of representation is yet incomplete, awaiting a work itself sets in motion. These symbolic depictions characteristic of television media, delineations referring to natural reality though lacking that reality's accompanying authority, or aura, now seek meaning from the receiver, bidding for their place, their correlation to the receiver's understanding.

That correlation, in Harshav's terms is dependent upon what he refers to as External Fields of Reference, "the real world in time and space."(29) Harshav argues that this is most significantly a relation pertaining to the reception of fiction works since non-fictional texts are immediately verifiable via these "additional texts or sources of information" to which it relates, direct referents to the material facts contained in the 
non-fiction work. This I find not so profound to the context of this discussion. If any text may be composed merely of direct referents - the real world in time and space - then reception and meaning could indeed be viewed as linear and television texts potentially deterministic since they would allow no space for contemplation. Thus confining this discussion of textual meaning to merely fictional works leaves us with a bifurcated understanding, a pronounced limitation to the complex I attempt to detail here, since the television universe is singly representational, symbolic, devoid of an inherent authority. So here I would liberally extend Harshav's application of additional texts. I would argue that in the case of technological reproduction, rooted at it is in a symbolic universe, the question of fictionality is immaterial since any representation so removed necessarily abandons an organic authority, awaiting what Lefebvre refers to as a labour of "symbolic process...the integration of...text to the spectator's imaginary," ${ }^{(30)}$ and the imaginary is shaped by an intricate construction of "philosophy, ideologies...human nature, society, technology, national character, psychology, religion, etc." which Harshav himself implies. ${ }^{(31)}$ It is this latter reference to the incorporeal which elaborates a broader understanding of the kind of additional texts necessary to adequately define and characterize the representations before us, and this consequently marks Harshav's most provocative ideations since it invokes the labour of reception.

\section{A Vision of Essences}

This is quite simply the illumination of a distinctive act, yet what exactly is the nature of that meaning? One assumes from ideas such as Harshav's that each individual brings to reception a unique construct informing one part of the reception complex, yet upon what foundation does meaning then arise or, perhaps more precisely, how and where does this intersection get worked out to finally construct some sort of meaning between text and receiver? I see this intersection as most acutely visual and representational. As viewers, what we behold before us is a televisual image of images, a recognizable world in representation and dependent upon the labour performed by the receiver to fully realize a meaning. That comprehension may be visually informed was critically and carefully exposed in the work of Jacques Lacan and his enlargement on earlier assertions by Henri Wallon. Lacan's ideas are rooted in the literal mirror of existence, what he calls a "vision of essences"(32) which represents a reception complex for psychological development, a juncture between intero- and exteroceptivity. Lacan's mirror theory, while not distinctly addressing television images, nevertheless furnishes us with one means for understanding the nature of representation and reception.

I must acknowledge here that my own reference to the Lacanian mirror risks invoking its pejorative link to the very idea of textual authoritarianism that Hall, Mayne and others decry. Proceeding as it did in the Althusserian, Post-Freudian climate of late 1960's French critical film discourse (the journals Cinéthique and Cahiers du Cinéma), and spreading in the 1970's to American critical thought in the works of Christian Metz $^{(33)}$ and Laura Mulvey ${ }^{(34)}$ among others, the mirror seemed the ideal means for understanding cinematic meaning and spectatorship, the key to deconstructing the ideological significations that were supposed to inhere in filmic texts. If such texts are merely contemporary versions of the Lacanian mirror, then reception may be understood as apprehensive. Like the infant before the literal mirror, the film text is a depiction meant to be taken literally, a mirror upon existence, a connection to the ideological structures that inform the context of its creation, and reception is simply the act of assuming the various stimuli contained in the mirror. Defining reception, then, is simply a deconstructive act; all one must do to understand its nature is to merely unravel the web of ideological meanings contained within the visual structure of the film text. To be certain, there is reason for concern here, yet also a glimmer of optimism that within the mirror itself resides a clue to its redemption from academic banishment, still a clue dependent first upon a thorough exposition of the mirror and its implications.

Lacan proceeds from the actual mirror, the specular image leading to critical understanding, in this case understanding of self. Building upon the work of others, most notably Henri Wallon ${ }^{(35)}$ who theorized that, among other things, our apprehension in the mirror before us marks a critical juncture in infant development, Lacan works out a most critical observation: one's understanding is most decidedly the product of a visual intersection. What the infant beholds in the mirror is particularly a democratic representation, an entire field in which no one visual stimulus reigns supremely over another. In other words, the mirror image is visually egalitarian, a complete frame, a complex of the image in aggregate. ${ }^{(36)}$ This fact alone suggests, I think, the futility of a strictly effects-oriented approach to understanding reception in which variable isolation will supposedly deliver a thorough understanding. If one acknowledges a visually egalitarian frame, how then 
does the logic of arresting a single visual variable from that frame fully account for meaning?

Yet this recapitulation alone fails to adequately connect the Lacanian mirror with its analog in television reception. The reflection is indeed apprehended before us, offering up its representation of an object world that is egalitarian, and certainly visual through and through, and Lacan equally views this as a means of understanding, yet the critical error here is assuming a linear authority to the mirror. That error conceals what should be an obvious dialectic and one which Lacan himself indeed delineates. The nature of the images before us is not literal reality, but a representation of that reality. Lacan admits as much when he notes "the relation of the imaginary and the real," and that "the position of the subject...is essentially characterized by its place in the symbolic world." ${ }^{(37)}$ If representation is thus symbolic, then reception proceeds from a context of verisimilitude, the depiction no longer dependent on a particular point in time and space, rather, like Freud's latter calculations on the window's representation, something to be worked out.

In this brief reference to the symbolic, one discovers the clue redeeming the Lacanian mirror from its academic and theoretical banishment in the reception arena, and the duality between imaginary and real, by staging the means for reception meaning, appeals to Benjamin's notion of meeting the beholder halfway. Visual comprehension, mediated as it is in technological media, is symbolic and dependent upon a rather complex intersection. Before us lays the aggregated image projected, a mediation in an object universe of representations appearing to be true, having a "sense" of real existence, ${ }^{(38)}$ but really only referents lying in wait.

\section{The Labour of Reception}

In an intriguing case for just such a position, Murray Smith fleshes out the negotiation thesis by contending that the critical agent in this labour is imagination, though not imagination in the traditional sense of "flight of fancy," rather an act marked by comprehension and interpretation, in which the viewer will make "inferences, formulate hypotheses, [and] categorize representations." ${ }^{(39)}$ This is perfectly consistent with the notion of a reception complex, for Smith clearly indicates imagination is a negotiative act depending upon one's ability to filter a given text's web of images through the cognitive conduit of his or her experiences and, most interestingly, Smith escapes the temptation to posit imagination as a sole, autocratic agent in meaning construction, a shortcoming which, as earlier stated, eclipses the no-less-critical role of text in the reception complex. Instead, Smith reminds the reader that imaginative acts are also guided and constrained by the text itself. ${ }^{(40)}$

Smith's point represents a careful structure for a negotiation reception complex. A given text possesses meaning, to be sure, yet meaning that is not yet complete, rather, a potential meaning that must be acted upon. This appears to complement Benjamin's concern for the loss of the object's aura in reproductive media. There is no need to moan that loss since legitimate meaning may yet arise, though not the meaning inhering in the object's original aura. Rather this is now the new meaning arising from this exercise of one's imagination, exactly the point Lefebvre makes. The work of reception for him, as it is for Smith, is "the work of the imagination...more precisely, the...result of an interaction between the [text], on the one hand, and the memory and imagination of the spectator, on the other." ${ }^{(41)}$

I find Lefebvre's illuminations quite consistent with the reception complex I propose since he locates textual meaning in an acutely visual context and carefully constructs a meaningful interpretation of the actual labour of reception. His work in his essay titled, On Memory and Imagination in the Cinema, carefully indicates the necessity of entertaining meaning origin in any formulation of a reception complex, for there can be no textual meaning absent the "impression" housed within the text itself and which leaves its "trace in the soft wax of [a spectator's] memory." ${ }^{(42)}$ To be sure, Lefebvre indicates, any text is open to infinite interpretation. He uses as example Edo's reference to the reading of a train's schedule which, in its extreme, could potentially be read as a narrative, a geographical alignment with a particular narrative line. In other words, it's not that infinite variability in meaning construction is impossible; it's just that such a reading produces, as Eco so adequately explains, "poor results,"(43) or viewed another way, an insufficient reading. Lefebvre is careful to suggest that complete meaning emerges from within the text itself, "must be supported by [its] elements." ${ }^{(44)}$

Referring to Sergei Eisenstein's exploitations of cinematic viewing, Lefebvre first points to a "privileged moment" that somehow initially attracts a viewer's attention, "make[s] an impression on him." (45) This is 
quite different, however, from the representation exclusive to the text's depiction; "it is an internal image ... distinguished from the material image depicted on screen." ${ }^{(46)}$ For Lefebvre, however, Eisenstein's formulations fall short of a thorough explanation for reception since they are designed to ultimately serve directorial ends, a means to dictate the workings of the viewer's imagination, direct the viewer to given understandings and conclusions and thus represent a false kind of ownership. The attraction that occurs in spectatorship that initiates the viewer's cognitive action does not, according to Lefebvre, belong to a given text, but is an "internal representation, which belongs to the spectator." ${ }^{(47)}$ He describes this action as an appropriation, an integration of the text's representations into one's imaginary.

One takes from such positions that reception in mechanical and electronic media may be viewed as processive, a "selective causal chain," as Uhlmann describes it, the image that is "consistent with the nature of my own being," refers to that nature, but which likewise carries with it the "full weight of potential meaning"(48) only finally realized as I receive the projected images, sifting, filtering, concentrating on those visual stimuli with which I might potentially interact and eliminating those which hold no connection for me.

\section{Conclusion}

I shall return here to the original proposition of this writing, that is, the inadequacy of the dominant investigative modalities in the field of television studies - effects - oriented approaches - to definitively explain and describe the nature of the complexities of reception. The limitations of linear authority should be obvious, as should its antithesis residing in notions of infinite variability and arising from a strict reliance on the given receiver's particular context of existence. The final alternative to understanding reception - negotiation may seem less precise since it lacks the statistical and mathematical precision of effects orientations, yet it nevertheless reveals a richer formulation of just what constitutes reception, or more accurately, meaning construction in a representational universe such as television, the intersection between text and receiver, a complex dependent on an image of images no longer possessed of an organic authority, but representing a spectral frame open to potential meaning. The text may no longer be viewed as isolated monolith, a structure of variables open to manipulation and measurement, and the receiver no longer a tabula rasa passively awaiting determination, but now a site of active labour, a construction of meaning performed at the intersection between representation and reception, a true negotiation between the text and receiver. This marks reception as a dynamic act, a complex providing the space for textual significance and agency on the part of the receiver.

\section{Notes}

1. Freud, Sigmund. Standard Edition of the Complete Psychological Works of Sigmund Freud, Vol. XVII. London: Hogarth Press, 1958, 248.

2. Medsger, Betty. Winds of Change: Challenges Confronting Journalism Education. Arlington: The Freedom Forum, 1996, 55.

3. Spencer, Herbert. The Study of Sociology. NY: Appleton and Company, 1882, 49.

4. Dealey, James Q. and Lester F. Ward. A Text-Book of Sociology. NY: The Macmillan Company, 1905, 8.

5. Hawkins, Robert P., Suzanne Pingree, Lisa Bruce, and John Tapper. "Strategy and Style in Attention to Television." Journal of Broadcasting and Electronic Media 41 (1997): 245-264.

6. Cantor, Joanne and Amy I. Nathanson. "Predictors of Children's Interest in Violent Television Programs." Journal of Broadcasting and Electronic Media 41 (1997): 55-168.

7. Lowe, Philip J. and Kevin Durkin. "The Effect of Flashback on Children's Understanding of Television Crime Content." Journal of Broadcasting and Electronic Media 43 (1999): 83-97.

8. Hoijer, Birgitta. "Socio-Cognitive Structures and Television Reception." Media, Culture and Society 14 (1992): 584 .

9. Press Andrea. "Toward a Qualitative Methodology of Audience Study: Using Ethnography to Study the Popular Culture Audience." In The Audience and its Landscape, edited by James Hay, Lawrence Grossberg 
and Ellen Wartella, 113 (Boulder: Westview Press, 1996).

10. Morley, David. Television Audiences and Cultural Theory. London: Routledge, 1992, 18.

11. Mayne, Judith. "Paradoxes of Spectatorship." In Viewing Positions: Ways of Seeing Film, edited by Linda Williams, 157 (New Brunswick, NJ: Rutgers University Press, 1995.

12. Mayne, "Paradoxes of Spectatorship," 157.

13. Hall, Stuart. "The Problem of Ideology: Marxism Without Guarantees." Journal of Communication Inquiry 10 (1986): 29.

14. Hall, Alice, Todd Anten, and Idil Cakim. "Perceived Typicality: American Television as Seen by Mexicans, Turks, and Americans." Critical Studies in Media Communication 16 (1999): 436-455.

15. Fetveit, Arild. "Reality TV in the Digital Era: A Paradox in Visual Culture?" Media, Culture ES Society 21 (1999): 787-804.

16. Mayne, "Paradoxes of Spectatorship," 158.

17. Hoijer, 586.

18. McKee, Kathy B., and Carol J. Pardun. "Reading the Video: A Qualitative Study of Religious Images in Music Videos." Journal of Broadcasting and Electronic Media 43 ((1999): 110- 122.

19. Benjamin, Walter. "The Work of Art in the Age of Mechanical Reproduction." In Illuminations: Essays and Reflections, edited by Hannah Arendt, 220 (NY: Harcourt, Brace \& World, 1936/1968).

20. Benjamin, 221.

21. Benjamin, 225.

22. Benjamin, 220.

23. Benjamin, 226.

24. Mayne, Judith. Cinema and Spectatorship. NY: Routledge, 1993, 102.

25. Mayne. Cinema and Spectatorship, 28.

26. Keating, Patrick. "The Fictional Worlds of Neorealism." Criticism 45 (2003): 11-30.

27. Harshav, Benjamin. "Fictionality and Fields of Reference: Remarks on a Theoretical Framework. Poetics Today 5 (1984): 230.

28. Keating, 14.

29. Harshav, 243.

30. Lefebvre, Martin. "On Memory and Imagination in the Cinema." New Literary History 30 (1999): 480.

31. Harshav, 243.

32. Borsch-Jacobsen, Mikkel. Lacan: The Absolute Master, trans. Douglas Brick, 63. (Stanford: Stanford University Press, 1991).

33. Christian Metz. Film Language; A Semiotics of the Cinema, trans. Michael Taylor. NY: Oxford University Press, 1974.

34. Mulvey, Laura. "Visual Pleasure and Narrative Cinema." Screen 16 (1975): 6-18.

35. Wallon, Henri. Les origines du caractère chez l'enfant: Les préludes du sentiment de personnalité, Paris: Presses Universitaires de France, 1945.

36. Lacan, Jacques. The Seminar of Jacques Lacan: Book II. The Ego in Freud's Theory HTML clipboard and in the Technique of Psychoanalysis, 1954-1955, trans. Sylvana Tomaselli, 121-122 and 140-141. (NY: Norton, 
1975/1988).

37. Lacan, The Seminar of Jacques Lacan: Book II. The Ego in Freud's Theory and in the Technique of Psychoanalysis, 1954-1955, 80.

38. Pence, Jeffrey. "Cinema of the Sublime: Theorizing the Ineffable." Poetics Today 25 (2004): 32.

39. Smith, Murray. "Altered States: Character and Emotional Response in the Cinema." Cinema Journal 33(1994): 35.

40. Smith, 35 .

41. Lefebvre, 480.

42. Ibid.

43. Eco, Umberto. Les limites de l'interpretation, trans. Martin Lefebvre. (Paris: Grasset, 1992).

44. Lefebvre, 493.

45. Lefebvre, 481.

46. Lefebvre, 482.

47. Lefebvre, 484.

48. Uhlmann, Anthony. "Image and Intuition in Beckett's Film." SubStance 33 (2004): 91.

\section{Author Information}

George BAGLEY is Associate Professor of Radio-Television at the University of Central Florida. His research addresses issues of film /television reception theory. He has published in academic journals such as The Journal of Film and Video, Critical Studies in Media Communication and Visual Communication Quarterly. 